\title{
Characterizing peritoneal dialysis catheter use in pediatric patients after cardiac surgery
}

\author{
Arin L. Madenci, AB, ${ }^{\mathrm{a}, \mathrm{b}}$ Ravi R. Thiagarajan, MBBS, MPH, ${ }^{\mathrm{c}}$ Alexander P. Stoffan, MD, ${ }^{\mathrm{b}, \mathrm{d}}$ \\ Sitaram M. Emani, MD, ${ }^{\mathrm{e}}$ Satish K. Rajagopal, MD, ${ }^{\mathrm{c}}$ and Christopher B. Weldon, MD, $\mathrm{PhD}^{\mathrm{d}}$
}

\begin{abstract}
Objective: Children who undergo cardiac surgery are at high risk for renal insufficiency and abdominal compartment syndrome. Peritoneal dialysis catheter (PDC) implantation is used in this population for abdominal decompression and access for dialysis. However, there is no consensus regarding PDC use, and the practice varies widely. This study was undertaken to assess associated factors, outcomes, and variability in the use of PDC in patients who have undergone cardiac surgery.
\end{abstract}

\begin{abstract}
Methods: The cohort was obtained from the Kids' Inpatient Database, years 2006 and 2009. Patients who underwent cardiac surgery were included and the subset that underwent PDC implantation during the same hospitalization was identified. Univariable and multivariable analyses assessed factors associated with PDC and survival.
\end{abstract}

Results: A cohort of 28,259 patients underwent cardiac surgery, of whom $558(2 \%)$ had PDCs placed. In the PDC group, $39.1 \%(n=218)$ had acute renal failure whereas $3.5 \%$ or patients $(n=974)$ in the non-PDC group had acute renal failure. Among patients receiving PDC, mortality was $20.3 \%(n=113$; vs $3.4 \%$ overall mortality, $\mathrm{n}=955)$. Excluding patients with acute renal failure, mortality remained $12 \%(\mathrm{n}=41)$ for the PDC group. Factors associated significantly with PDC placement in the overall cohort were younger age, greater surgical complexity, nonelective admission, hospital region, use of cardiopulmonary bypass, and acute renal failure.

Conclusions: Patients receiving PDC after cardiac surgery had 20\% mortality, which remained $12 \%$ after excluding patients with acute renal failure. Given the variability in PDC use and poor outcomes, further research is needed to assess the possible benefit of earlier intervention for peritoneal access in this high-risk cohort. (J Thorac Cardiovasc Surg 2013;146:334-8)

Children who undergo cardiac surgery are at risk for venous hypertension and low systemic perfusion, which may contribute to the development of ascites, abdominal compartment syndrome, decreased renal perfusion, and renal insufficiency. Renal insufficiency, which affects less than $10 \%$ of children who undergo cardiopulmonary bypass (CPB), worsens fluid overload and extravasation further. ${ }^{1-3}$ The catheter may function to decompress a hypertensive peritoneal cavity ${ }^{4}$ or to alleviate the burden of renal insufficiency. ${ }^{5}$ Allowing drainage of fluid is hypothesized to alleviate local renal compression and hasten the return of renal function, including via the removal of proinflammatory cytokines. ${ }^{1,6}$ The majority of the time, permanent peritoneal access is used solely for fluid drainage and dialysis is not required. ${ }^{7}$

\footnotetext{
From the University of Mich Medical School, ${ }^{\mathrm{a}}$ Ann Arbor, Mich; Harvard School of Public Health, ${ }^{\mathrm{b}}$ Boston, Mass; Departments of Cardiology, ${ }^{\mathrm{c}}$ Surgery, ${ }^{\mathrm{d}}$ and Cardiac Surgery, ${ }^{\mathrm{e}}$ Boston Children's Hospital and Harvard Medical School, Boston, Mass. Disclosures: Authors have nothing to disclose with regard to commercial support. Received for publication July 17, 2012; revisions received Sept 19, 2012; accepted for publication Oct 2, 2012; available ahead of print Nov 12, 2012.

Address for reprints: Christopher B. Weldon, MD, PhD, Department of Surgery, 300 Longwood Ave, Fegan 3, Boston, MA 02115 (E-mail: christopher.weldon@ childrens.harvard.edu).

$0022-5223 / \$ 36.00$

Copyright (c) 2013 by The American Association for Thoracic Surgery http://dx.doi.org/10.1016/j.jtcvs.2012.10.009
}

It remains unknown whether permanent peritoneal access confers a clinical benefit. Information on outcomes for pediatric patients who undergo peritoneal dialysis catheter (PDC) placement after cardiac surgery is lacking. A systematic evaluation has been difficult to conduct in this population because of the uniqueness of the patient cohort that undergoes cardiac surgery and goes on to receive a PDC. In addition, the practice is not standardized. Some surgeons advocate the use of early prophylactic PDCs in the majority of postcardiac surgery patients whereas others take the approach of active monitoring. ${ }^{8}$ It is equally unclear whether the benefit of PDCs lies in true peritoneal dialysis or in decompression for abdominal compartment syndrome, in which case temporary access may be less invasive and equally beneficial. The current study uses the Healthcare Cost and Utilization Project Kids' Inpatient Database (KID) to characterize associated factors, outcomes, and variability in the use of PDCs in patients who have undergone cardiac surgery.

\section{METHODS \\ Data Source}

The KID, created by the Agency for Healthcare Research and Quality, was used to conduct this study. The KID was developed as part of the Healthcare Cost and Utilization Project, which is a federal-state-industry 


\section{Abbreviations and Acronyms \\ $\mathrm{ARF} \quad=$ acute renal failure \\ $\mathrm{CPB}=$ cardiopulmonary bypass \\ ICD-9-CM = International Classification of \\ Diseases, 9th revision, clinical modification \\ KID = Kids' Inpatient Database \\ PDC = peritoneal dialysis catheter \\ RACHS-1 = Risk Adjustment for Congenital Heart Surgery}

partnership, and contains information regarding diagnoses, procedures, patient demographics, payment source, total charges, and hospital characteristics. The database samples randomly and systematically $10 \%$ of uncomplicated in-hospital births and $80 \%$ of admissions for pediatric patients (age $<21$ years). The KID is released every 3 years, and for this study, the most recent 2 editions (2006 and 2009) were used. Up to 15 diagnoses and 15 procedures are included in the 2006 KID whereas up to 25 diagnoses and 15 procedures are included in the 2009 KID.

All patients who underwent cardiac surgery were included, as assessed by the International Classification of Diseases, 9th revision, clinical modification (ICD-9-CM) procedure and diagnosis codes. To identify PDC placement, the ICD-9-CM code 54.93 (Creation of cutaneoperitoneal fistula) was used. To assess severity of congenital cardiac disease, the Risk Adjustment for Congenital Heart Surgery (RACHS-1) category was evaluated based on ICD-9-CM procedure codes. ${ }^{9,10}$ A RACHS- 1 risk score of 1 entails the lowest risk category whereas a risk score of 6 entails the highest risk category. In the event that a patient was able to be grouped into 2 or more RACHS-1 categories, the highest risk score was selected. The RACHS-1 adjustment also takes into account age at the time of cardiac operation, prematurity, presence of major noncardiac structural anomaly, and multiple cardiac procedures. Categories 1 and 2, and 5 and 6 of the RACHS1 were combined to preclude reporting $<11$ observations in any given cell, in accordance with the with the Agency for Healthcare Research and Quality data use agreement. If a RACHS-1 category was unable to be assigned (eg, patients undergoing heart transplantation), patients were classified as unassigned. Patients who underwent CPB were identified using ICD-9CM code 39.61 (Extracorporeal circulation auxiliary to open heart surgery). Patients who developed acute renal failure (ARF) were identified by the ICD-9-CM diagnostic codes 584.9 (Acute renal failure, unspecified), 586 (Renal failure, unspecified), and 639.3 (Renal failure). Peritoneal dialysis was identified by the ICD-9-CM procedure code 54.98 (Peritoneal dialysis).

\section{Statistical Analysis}

We tabulated patient demographics, hospitalization characteristics, clinical data, and survival for the patient cohort based on weighted estimates that account appropriately for the KID sampling methodology. Reported percentages are based on available data for each variable. We assessed univariable associations with PDC using the Rao-Scott $\chi^{2}$ test statistic. Next, adjusted odds ratios for PDC use were obtained from a weighted multivariable logistic regression model. To evaluate the use of PDCs for nonrenal failure indications, a multivariable analysis for PDC use was performed for the subcohort of patients without ARF. The relationship of clinical and health services factors with mortality in the overall cohort was then assessed in a multivariable model. Stepwise selection was used in all multivariable analyses. Patients with missing data were excluded from each respective univariable and multivariable analysis. An alpha level of $5 \%$ was considered statistically significant. All data were analyzed using SAS 9.3 (SAS Institute, Inc, Cary, NC).

\section{RESULTS \\ Overall Characteristics}

Baseline characteristics of the KID patients included for analysis are reported in Table 1. A total 28,259 cardiac surgery cases were identified. There were an approximately equal proportion of male $(54.8 \%, \mathrm{n}=15,446)$ and female as well as white $(51.5 \%, \mathrm{n}=11,994)$ and nonwhite patients. The distribution of RACHS-1 categories was $37.7 \%$ $(\mathrm{n}=10,646)$ in categories 1 and $2,30.1 \%(\mathrm{n}=8502)$ in category $3,7.8 \%(\mathrm{n}=2204)$ in category 4 , and $2.2 \%$ $(\mathrm{n}=621)$ in categories 5 and 6 . There were $22.2 \%$ of patients $(n=6286)$ who were unable to be assigned a RACHS-1 category. There were $4.2 \%$ of patients $(\mathrm{n}=1192)$ who were diagnosed with ARF, which carried a mortality rate of $23.7 \%(\mathrm{n}=282)$. Most admissions were elective $(59.9 \%, \mathrm{n}=16,930)$.

In this cohort, $2 \%(n=558)$ of patients had a PDC placedduring the same hospitalization. Overall mortality was $3.4 \%$ $(\mathrm{n}=955)$. Among patients who underwent PDC placement, mortality was $20.3 \%(n=113) ; 39.1 \%$ of patients $(n=218)$ who underwent PDC placement were diagnosed with ARF. Of the patients who received a PDC, a minority underwent peritoneal dialysis $(21.3 \%, \mathrm{n}=119)$. Forty-two patients in the non-PDC group $(0.15 \%)$ underwent peritoneal dialysis via a preexisting catheter that was not placed during the same hospitalization as the cardiac surgery. Some patients $(0.6 \%, \mathrm{n}=182)$ underwent paracentesis without the implantation of permanent peritoneal access.

\section{Factors Associated With PDC Use}

In the unadjusted analysis, factors associated with PDC use included age group $(P<.01)$, RACHS- 1 category $(P<.01)$, nonelective admission $(P<.01)$, hospital region $(P<.01)$, insurance status $(P=.02)$, and ARF $(P<.01)$. Other univariable associations are reported in Table 1 . To control for confounding, we next performed a multivariable stepwise regression analysis. Younger age, higher RACHS1 category, nonelective admission, South or West hospital region, $\mathrm{CPB}$, and $\mathrm{ARF}$ were associated significantly with PDC use. Table 2 reports the adjusted odds ratios for the factors associated with PDC use. In addition, we evaluated the use of PDCs for nonrenal failure indications. Factors associated significantly with PDC use in the subset of patients without ARF included younger age, higher RACHS-1 category, nonelective admission, South or West hospital region, and CPB. The adjusted odds ratios were similar to those of the overall cohort, as reported in Table 3.

\section{Outcome}

Mortality in the group of patients who received PDCs was $20.3 \%(n=113)$, compared with $3.0 \%(n=842)$ for patients did not receive PDCs. Mortality rates for patients with PDCs who had ARF and did not have ARF 
TABLE 1. Baseline characteristics and outcomes for patients who did or did not undergo peritoneal dialysis catheter implantation

\begin{tabular}{|c|c|c|c|c|}
\hline Variable & $\begin{array}{c}\text { Overall, } \\
\text { n }(\%)\end{array}$ & $\begin{array}{l}\text { PDC, } \\
\text { n }(\%)\end{array}$ & $\begin{array}{c}\text { No PDC, } \\
\text { n }(\%)\end{array}$ & $\begin{array}{c}P \\
\text { value }\end{array}$ \\
\hline Sample size & $28,259(100)$ & $558(2.0)$ & $27,701(98.0)$ & \\
\hline Female sex $(n=28,186)$ & $12,740(45.2)$ & $248(44.4)$ & $12,492(45.2)$ & .74 \\
\hline Age group $(n=24,813)$ & & & & $<.01$ \\
\hline 0 to $30 \mathrm{~d}$ & $6169(24.9)$ & $206(59.0)$ & $5963(24.4)$ & \\
\hline $1 \mathrm{mo}$ to $1 \mathrm{y}$ & $6982(28.1)$ & $69(19.8)$ & $6913(28.3)$ & \\
\hline $1 \mathrm{y}$ to $18 \mathrm{y}$ & $11,662(47.0)$ & $74(21.2)$ & $11,588(47.4)$ & \\
\hline White race $(\mathrm{n}=23,289)$ & $11,994(51.5)$ & $236(47.1)$ & $11,758(51.6)$ & .40 \\
\hline RACHS-1 category & & & & $<.01$ \\
\hline 1 to 2 & $10,646(37.7)$ & $77(13.8)$ & $10,569(38.1)$ & \\
\hline 3 & $8502(30.1)$ & $187(33.5)$ & $8315(30.0)$ & \\
\hline 4 & $2204(7.8)$ & $116(20.8)$ & $2088(7.5)$ & \\
\hline 5 to 6 & $621(2.2)$ & $54(9.7)$ & $567(2.0)$ & \\
\hline Unassigned & $6286(22.2)$ & $124(22.2)$ & $6162(22.2)$ & \\
\hline Nonelective admission & $11,329(40.3)$ & $428(76.8)$ & $10,901(39.5)$ & $<.01$ \\
\hline Hospital region & & & & $<.01$ \\
\hline Northeast & $4346(15.4)$ & $14(2.5)$ & $4332(15.6)$ & \\
\hline Midwest & $6498(23.0)$ & $71(12.7)$ & $6427(23.2)$ & \\
\hline South & $9710(34.4)$ & $364(65.2)$ & $9346(33.7)$ & \\
\hline West & $7705(27.3)$ & $109(19.5)$ & $7596(27.4)$ & \\
\hline $\begin{array}{l}\text { Teaching hospital } \\
\quad(\mathrm{n}=25,917)\end{array}$ & $24,544(94.7)$ & $423(96.8)$ & $24,121(94.7)$ & .34 \\
\hline Insurance $(\mathrm{n}=28,239)$ & & & & .02 \\
\hline Private & $13,120(46.5)$ & $243(43.5)$ & $12,877(46.5)$ & \\
\hline Medicaid & $12,640(44.7)$ & $282(50.5)$ & $12,358(44.6)$ & \\
\hline Other & $2479(8.8)$ & $33(5.9)$ & $2446(8.8)$ & \\
\hline $\mathrm{CPB}$ & $21,002(74.3)$ & $429(76.9)$ & $20,573(74.3)$ & .63 \\
\hline ARF & $1192(4.2)$ & $218(39.1)$ & $974(3.5)$ & $<.01$ \\
\hline Died & $955(3.4)$ & $113(20.3)$ & $842(3.0)$ & $<.01$ \\
\hline
\end{tabular}

were $33.0 \%(n=72)$ and $12.0 \%(n=41)$, respectively, as shown in Table 4 . We performed a multivariable analysis of mortality, which is displayed in Table 5. Placement of a PDC was not included in the model to avoid confounding by indication. Variables associated significantly with mortality included younger age group, RACHS-1 category, nonelective admission, nonprivate insurance, and ARF. Hospital region was not associated with mortality.

\section{DISCUSSION}

The mortality for patients who had PDCs implanted after cardiac surgery was $20 \%$. Excluding patients with ARF from the analysis, mortality for the PDC group remained $12 \%$. Factors associated significantly with PDC placement included younger age, greater surgical complexity, nonelective admission, South or West hospital region, CPB, and ARF. Based on the variability observed in this study, the decision to implant PDCs is not standardized. It is possible that earlier, prophylactic intervention with a PDC may confer a mortality benefit in the appropriate cohort of patients. Demographic (young age), clinical (CPB and ARF), and
TABLE 2. Multivariable stepwise analysis of the factors associated with peritoneal dialysis catheter use

\begin{tabular}{lccr}
\hline \multicolumn{1}{c}{ Variable } & $\begin{array}{c}\text { Adjusted } \\
\text { odds ratio }\end{array}$ & $\begin{array}{c}\mathbf{9 5} \% \text { Confidence } \\
\text { interval }\end{array}$ & $\begin{array}{c}\boldsymbol{P} \\
\text { value }\end{array}$ \\
\hline Age group (vs $\leq 30 \mathrm{~d})$ & & & \\
$\quad$ 1 mo to 1 y & 0.61 & $0.33-1.12$ & .11 \\
1 y to 18 y & 0.30 & $0.18-0.51$ & $<.01$ \\
RACHS-1 category (vs 1-2) & & & \\
3 & 1.72 & $1.28-2.32$ & $<.01$ \\
4 & 2.74 & $1.76-4.26$ & $<.01$ \\
5-6 & 2.74 & $1.35-5.56$ & $<.01$ \\
Unassigned & 0.89 & $0.49-1.63$ & .70 \\
Nonelective admission & 3.11 & $1.18-8.19$ & .02 \\
Hospital region (vs Northeast) & & & \\
Midwest & 2.10 & $0.71-6.18$ & .17 \\
South & 19.35 & $4.33-88.19$ & $<.01$ \\
West & 4.11 & $1.47-11.53$ & $<.01$ \\
CPB & 2.35 & $1.10-5.02$ & .03 \\
ARF & 13.15 & $7.43-23.28$ & $<.01$ \\
\hline S
\end{tabular}

Stepwise model included sex, age group, race, RACHS-1 category, elective admission, hospital region, teaching hospital, insurance status, CPB, and ARF. RACHS-1, Risk adjustment for congenital heart surgery; $C P B$, cardiopulmonary bypass; $A R F$, acute renal failure.

systems (nonelective admission) factors were found to be associated with PDC use in our study. These associations may be useful in selecting patients in whom to perform early PDC placement. Neonatal age was associated with a 2- to 5-fold increase in PDC use in our study. Furthermore, age has been shown to be an independent risk factor for postoperative $\mathrm{ARF}^{11}$ and mortality. ${ }^{12}$ As such, some highrisk young patients may benefit from prophylactic PDCs. Presence and severity of ARF are likewise associated with postoperative mortality. ${ }^{13}$ In our study, ARF carried an

TABLE 3. Multivariable stepwise analysis of the factors associated with peritoneal dialysis catheter use among patients without acute renal failure

\begin{tabular}{lccr}
\hline \multicolumn{1}{c}{ Variable } & $\begin{array}{c}\text { Adjusted } \\
\text { odds ratio }\end{array}$ & $\begin{array}{c}\mathbf{9 5} \% \text { Confidence } \\
\text { interval }\end{array}$ & $\begin{array}{c}\boldsymbol{P} \\
\text { value }\end{array}$ \\
\hline Age group (vs $\leq 30 \mathrm{~d}$ ) & & & \\
$\quad$ 1 mo to 1 y & 0.49 & $0.26-0.91$ & .02 \\
1 to 18 y & 0.18 & $0.09-0.34$ & $<.01$ \\
RACHS-1 category (vs 1-2) & & & \\
3 & 1.78 & $1.32-2.40$ & $<.01$ \\
4 & 2.09 & $1.20-3.63$ & $<.01$ \\
5 to 6 & 3.44 & $1.63-7.27$ & $<.01$ \\
$\quad$ Unassigned & 1.21 & $0.63-2.32$ & .58 \\
Nonelective admission & 3.76 & $1.38-10.21$ & $<.01$ \\
Hospital region (vs Northeast) & & & \\
Midwest & 2.99 & $0.96-9.32$ & .06 \\
South & 48.59 & $14.05-168.05$ & $<.01$ \\
$\quad$ West & 6.93 & $2.90-16.56$ & $<.01$ \\
CPB & 4.64 & $2.01-10.69$ & $<.01$ \\
\hline
\end{tabular}

Stepwise model included sex, age group, race, RACHS-1 category, elective admission, hospital region, teaching hospital, insurance status, and CPB. RACHS-1, Risk adjustment for congenital heart surgery; $C P B$, cardiopulmonary bypass. 
TABLE 4. Mortality stratified by ARF and PDC groups

\begin{tabular}{lcccccccc}
\hline & \multicolumn{3}{c}{ ARF } & & \multicolumn{3}{c}{ No ARF } \\
\cline { 2 - 3 } \cline { 6 - 8 } Variable & PDC & No PDC & $\boldsymbol{P}$ value & & PDC & No PDC & $\boldsymbol{P}$ value \\
\hline Sample size & 218 & 974 & & 340 & 26,727 & \\
Died $(\%)$ & $72(33.0)$ & $210(21.6)$ & .13 & & $41(12.1)$ & $632(2.4)$ & $<.01$ \\
\hline
\end{tabular}

$A R F$, Acute renal failure; $P D C$, peritoneal dialysis catheter.

8-fold increase in PDC placement. An inciting factor for renal injury in this patient population is often CPB. ${ }^{14-16}$ Acute renal failure has been shown to be 7 times more likely with CPB time $>2$ hours. ${ }^{14}$ Nearly $75 \%$ of the patients in our cohort underwent CPB. Shorter time to starting peritoneal dialysis after ARF has been found to be associated with increased postoperative survival after congenital cardiac surgery. ${ }^{17,18}$ The timing of PDC implantation relative to serum markers of renal function will fill an important knowledge gap in the management of cardiac surgery patients.

The elevated mortality rate of the cohort who received PDCs may be related to the indications for PDC placement - namely, ARF and intra-abdominal hypertension. Patients who develop these conditions after cardiac surgery are known to fare worse than their counterparts who are not afflicted with these pathophysiologies. ${ }^{17,19}$ This argument may be supported by our finding that, limited to patients without ARF, the mortality rate for the PDC cohort was attenuated from $20 \%$ to $12 \%$. We were not able to assess the presence of intra-abdominal hypertension.

The association of nonelective admission with increased PDC use and mortality in our study may reflect a lack of response to outpatient management or postoperative physiologic decompensation. Not surprisingly, the most common reason for the readmission of patients with congenital heart

TABLE 5. Multivariable stepwise analysis of the factors associated with mortality

\begin{tabular}{lccc}
\hline \multicolumn{1}{c}{ Variable } & $\begin{array}{c}\text { Adjusted } \\
\text { odds ratio }\end{array}$ & $\begin{array}{c}\mathbf{9 5} \% \text { Confidence } \\
\text { interval }\end{array}$ & $\begin{array}{c}\boldsymbol{P} \\
\text { value }\end{array}$ \\
\hline Age group & & & \\
1 mo to 1 y (vs $\leq 30 \mathrm{~d})$ & 0.50 & $0.37-0.69$ & $<.01$ \\
1 to 18 y (vs $\leq 30 \mathrm{~d})$ & 0.26 & $0.19-0.36$ & $<.01$ \\
RACHS-1 category & & & \\
3 (vs 1-2) & 2.15 & $1.65-2.80$ & $<.01$ \\
4 (vs 1-2) & 3.21 & $2.25-4.58$ & $<.01$ \\
5 to 6 (vs 1-2) & 4.03 & $2.50-6.50$ & $<.01$ \\
$\quad$ Unassigned & 3.18 & $2.27-4.47$ & $<.01$ \\
Nonelective admission & 2.63 & $2.00-3.47$ & $<.01$ \\
Insurance & & & \\
$\quad$ Medicaid (vs private) & 1.35 & $1.10-1.66$ & $<.01$ \\
$\quad$ Other & 1.35 & $0.93-1.95$ & .12 \\
ARF & 7.18 & $5.42-9.52$ & $<.01$ \\
\hline
\end{tabular}

Stepwise model included sex, age group, race, RACHS-1 category, elective admission, hospital region, teaching hospital, insurance status, cardiopulmonary bypass, and ARF. RACHS-1, Risk adjustment for congenital heart surgery; $A R F$, acute renal failure. disease has been shown to be exacerbation of cardiac illness. ${ }^{20}$ In our study, patients who were admitted as an emergency and underwent cardiac surgery were at high risk for PDC and mortality. Emergency surgery is known to carry higher morbidity and mortality rates and poorer long-term outcomes. ${ }^{21}$ Previous research has focused on developing risk scores for patients undergoing nonelective surgery; however, after the highest risk patients have been identified, the appropriate intervention is often unclear. ${ }^{22}$ Given the 3 fold increased use of a PDC in patients who were admitted as an emergency in this study, 1 intervention that should be studied further is lowering the threshold to use PDCs for this cohort.

We found $>60 \%$ of PDCs placed in the absence of ARF. Mortality remained substantial at $12 \%$. Concern for abdominal compartment syndrome may have led to the PDC implantation in many of these patients, although literature on the incidence rates of PDC placement for indications other than renal replacement therapy is nonexistent. In patients with abdominal compartment syndrome, early establishment of peritoneal access may improve outcome; however, it is unclear whether PDC placement was a marker of disease or a therapeutic tool in our study.

It will also be useful to study the comparative effectiveness between PDCs and temporary peritoneal drains. The complication rate for the former is not insignificant, considering that the rate of peritonitis is 1 episode per 11.8 months in children $<2$ years who undergo PDC placement. ${ }^{23}$ For patients with ARF, temporary peritoneal access may be equally beneficial without the associated risks of a permanent catheter.

Ultimately, these findings suggest the need for a more robust set of guidelines for peritoneal access in patients who have recently undergone cardiac surgery. If clinical factors such as those identified in this study were able to identify characteristics associated with high risk of PDC placement, prophylactic intervention may be beneficial for patients predicted to need PDCs. Extra measures may need to be taken for this at-risk cohort. Such interventions could take the form of prophylactic or early PDC placement or a more definitive treatment in decompressive laparotomy.

\section{Limitations}

There are several limitations to these results. First, the study was limited by its retrospective cohort design with its inherent risk of confounding and bias. Second, by relying solely on data from the KID, bias could be introduced. The KID data were not collected specifically for the study of PDC use among patients after cardiac surgery, so important covariates may not have been included in the analysis. Granular clinical data such as the indication for and setting of (eg, intraoperative or bedside) PDC placement were unable to be ascertained. Likewise, data on important peritoneal dialysis characteristics such as concentrations, dwell times, and volumes were unable to be attained. We were 
not able to assess timing of PDC placement relative to cardiac surgery. Because the KID is an administrative database, there may be patients who underwent cardiac surgery or PDC placement who were not captured by procedure codes because of omission or miscoding. Given the multicenter nature of the data set, there was no control over variation in individual physician practices. Last, the KID relies on hospital discharge information and foregoes tracking of readmissions for a given patient. As such, the current study was unable to capture patients who underwent PDC placement after hospital discharge. This type of misclassification would likely be nondifferential and would therefore bias the result toward the null.

Despite the inherent limitations of using an administrative database such as the KID, this design does have several advantages. Foremost, the KID allows a large sample size for the relatively rare procedure of PDC placement in patients status postcardiac surgery. In addition, the KID presents a patient population sample that is captured randomly and systematically from the national population.

\section{CONCLUSIONS}

In conclusion, patients receiving PDCs after cardiac surgery are a high-risk population, with a $20 \%$ mortality rate. Younger age at operation, greater surgical complexity, nonelective admission, hospital region, and ARF were associated with PDC placement. Prospective clinical studies are needed to characterize more completely the indications, risks, and benefits of PDC placement in patients who have recently undergone cardiac surgery. Development of evidence-based practices for PDC placement in patients who have undergone cardiac surgery may be useful, given the substantial mortality rate in this population.

\section{References}

1. Kist-van Holthe tot Echten JE, Goedvolk CA, Doornaar MB, van der Vorst MM, Bosman-Vermeeren JM, Brand R, et al. Acute renal insufficiency and renal replacement therapy after pediatric cardiopulmonary bypass surgery. Pediatr Cardiol. 2001;22:321-6.

2. Pedersen KR, Hjortdal VE, Christensen S, Pedersen J, Hjortholm K, Larsen SH, et al. Clinical outcome in children with acute renal failure treated with peritoneal dialysis after surgery for congenital heart disease. Kidney Int Suppl. 2008;108: S81-6.

3. Stromberg D, Fraser CD Jr, Sorof JM, Drescher K, Feltes TF. Peritoneal dialysis: an adjunct to pediatric postcardiotomy fluid management. Tex Heart Inst J. 1997; 24:269-77.
4. Sugrue M. Abdominal compartment syndrome. Curr Opin Crit Care. 2005;11: 333-8.

5. Ash SR. Chronic peritoneal dialysis catheters: overview of design, placement, and removal procedures. Semin Dial. 2003;16:323-34.

6. Dittrich S, Aktuerk D, Seitz S, Mehwald P, Schulte-Monting J, Schlensak C, et al. Effects of ultrafiltration and peritoneal dialysis on proinflammatory cytokines during cardiopulmonary bypass surgery in newborns and infants. Eur J Cardiothorac Surg. 2004;25:935-40.

7. Alkan T, Akcevin A, Turkoglu H, Paker T, Sasmazel A, Bayer V, et al. Postoperative prophylactic peritoneal dialysis in neonates and infants after complex congenital cardiac surgery. ASAIO J. 2006;52:693-7.

8. Sorof JM, Stromberg D, Brewer ED, Feltes TF, Fraser CD Jr. Early initiation of peritoneal dialysis after surgical repair of congenital heart disease. Pediatr Nephrol. 1999;13:641-5.

9. Jenkins KJ, Gauvreau K, Newburger JW, Spray TL, Moller JH, Iezzoni LI. Consensus-based method for risk adjustment for surgery for congenital heart disease. J Thorac Cardiovasc Surg. 2002;123:110-8.

10. Jenkins KJ, Gauvreau K. Center-specific differences in mortality: preliminary analyses using the Risk Adjustment in Congenital Heart Surgery (RACHS-1) method. J Thorac Cardiovasc Surg. 2002;124:97-104.

11. Sethi SK, Goyal D, Yadav DK, Shukla U, Kajala PL, Gupta VK, et al. Predictors of acute kidney injury postcardiopulmonary bypass in children. Clin Exp Nephrol. 2011;15:529-34

12. Chang RK, Rodriguez S, Lee M, Klitzner TS. Risk factors for deaths occurring within 30 days and 1 year after hospital discharge for cardiac surgery among pediatric patients. Am Heart J. 2006;152:386-93.

13. Blinder JJ, Goldstein SL, Lee VV, Baycroft A, Fraser CD, Nelson D, et al. Congenital heart surgery in infants: effects of acute kidney injury on outcomes. J Thorac Cardiovasc Surg. 2012;143:368-74.

14. Rodrigues AJ, Evora PR, Bassetto S, Alves L Jr, Scorzoni Filho A, Vicente WV. Risk factors for acute renal failure after heart surgery. Rev Bras Cir Cardiovasc. 2009;24:441-6.

15. Bahar I, Akgul A, Ozatik MA, Vural KM, Demirbag AE, Boran M, et al. Acute renal failure following open heart surgery: risk factors and prognosis. Perfusion. 2005;20:317-22.

16. Baskin E, Gulleroglu KS, Saygili A, Aslamaci S, Varan B, Tokel K. Peritoneal dialysis requirements following open-heart surgery in children with congenital heart disease. Ren Fail. 2010;32:784-7.

17. Bojan M, Gioanni S, Vouhe PR, Journois D, Pouard P. Early initiation of peritoneal dialysis in neonates and infants with acute kidney injury following cardiac surgery is associated with a significant decrease in mortality. Kidney Int. 2012;82:474-81.

18. Chien JC, Hwang BT, Weng ZC, Meng LC, Lee PC. Peritoneal dialysis in infants and children after open heart surgery. Pediatr Neonatol. 2009;50:275-9.

19. Pearson EG, Rollins MD, Vogler SA, Mills MK, Lehman EL, Jacques E, et al. Decompressive laparotomy for abdominal compartment syndrome in children: before it is too late. J Pediatr Surg. 2010;45:1324-9.

20. Mackie AS, Ionescu-Ittu R, Pilote L, Rahme E, Marelli AJ. Hospital readmissions in children with congenital heart disease: a population-based study. Am Heart J. 2008; 155:577-84.

21. Ascanelli S, Navarra G, Tonini G, Feo C, Zerbinati A, Pozza E, et al. Early and late outcome after surgery for colorectal cancer: elective versus emergency surgery. Tumori. 2003;89:36-41.

22. Neary WD, Foy C, Heather BP, Earnshaw JJ. Identifying high-risk patients undergoing urgent and emergency surgery. Ann R Coll Surg Engl. 2006;88:151-6.

23. Ronnholm KA, Holmberg C. Peritoneal dialysis in infants. Pediatr Nephrol. 2006;21:751-6. 